\title{
Self-Recovery of Pancreatic Beta Cell's Insulin Secretion Based on 10+ Years Annualized Data of Food, Exercise, Weight, and Glucose Using GH- Method: Math-Physical Medicine (No. 339)
}

\author{
Gerald C Hsu* \\ EclaireMD Foundation, USA \\ ${ }^{\star}$ Corresponding author: Gerald C Hsu, EclaireMD Foundation, USA
}

Received: October 21, 2020; Accepted: October 29, 2020; Published: November 04, 2020

\begin{abstract}
The author was inspired from reading two recently published medical papers regarding pancreatic beta cells insulin secretion or diabetes reversal via weight reduction. The weight reduction is directly related to the patient's lifestyle improvement through diet and exercise. He has published six medical papers on beta cells based on different stages in observations of his continuous glucose improvements; therefore, in this article, he will investigate food ingredients, meal portions, weight, and glucose improvement based on his 10+ years of collected big data.
\end{abstract}

Here is the summary of his findings:

1. His successful weight reduction, from $220 \mathrm{lbs}$. in 2010 to $171 \mathrm{lbs}$. in 2020, comes from his food portion reduction and exercise increase.

2. His lower carbs/sugar intake amount, from 40 grams in 2010 to 12 grams in 2020, is resulted from his learned food nutrition knowledge and meal portion reduction, from $150 \%$ in 2010 to $67 \%$ in 2020 .

3. His weight reduction contributes to his FPG reduction, from $220 \mathrm{mg} / \mathrm{dL}$ in 2010 to $104 \mathrm{mg} / \mathrm{dL}$ in 2020 . His carbs/sugar control and increased walking steps, from 2,000 steps in 2010 to 16,000 steps in 202, have contributed to his PPG reduction, from $300 \mathrm{mg} / \mathrm{dL}$ in 2010 to $109 \mathrm{mg} / \mathrm{dL}$ in 2020. When both FPG and PPG are reduced, his daily glucose is decreased as well, from $280 \mathrm{mg} / \mathrm{dL}$ in 2010 to $108 \mathrm{mg} / \mathrm{dL}$ in 2020 .

4. His damaged beta cell's insulin production and functionality, most likely, have been repaired about $16 \%$ for the past 6 years or $27 \%$ in the past 10 years at a self-repair rate of $2.7 \%$ per year.

The conclusion from this paper is a $2.7 \%$ annual beta cells self-repair rate which is similar to his previously published papers regarding his range of pancreatic beta cells self-recovery of insulin secretion with an annual rate between $2.3 \%$ to $3.2 \%$.

To date, the author has written seven papers discussing his pancreatic beta cell's self-recovery of insulin secretion. In his first six papers [1-7], he used several different "cutting angles" or "analysis approaches" to delve deeper into this complex biomedical subject and achieved consistent results within the range of $2.3 \%$ to $3.2 \%$ of annual self-recovery rate.

He used a quantitative approach with precision to discover and reconfirm his pancreatic beta cell's health state by linking it backwards step-by-step with his collected data of glucose, weight, diet, and exercise. He has produced another dataset for a self-repair rate of $2.7 \%$ which is located right in the middle between $2.3 \%$ and $3.2 \%$ from his previous findings.

In his opinion, type 2 diabetes (T2D) is no longer a non-reversible or non-curable disease. Diabetes is not only "controllable" but it is also "selfrepairable", even though at a rather slow rate. He would like to share his research findings and his persistent efforts from the past decade with his medical research colleagues and to provide encouragement to motivate other T2D patients like himself to reverse their diabetes conditions.

\section{Introduction}

The author was inspired from reading two recently published medical papers regarding pancreatic beta cells insulin secretion or diabetes reversal via weight reduction. The weight reduction is directly related to the patient's lifestyle improvement through diet and exercise. He has published six medical papers on beta cells based on different stages in observations of his continuous glucose improvements; therefore, in this article, he will investigate food ingredients, meal portions, weight, and glucose improvement based on his $10+$ years of collected big data. 


\section{Methods}

\section{Background}

To learn more about his developed GH-Method: math-physical medicine (MPM) research methodology, readers can review his article, Biomedical research methodology based on GH-Method: mathphysical medicine (No. 54 and No. 310), in Reference [1] to understand his MPM analysis method.

\section{Diabetes History}

In 1995, the author was diagnosed with severe type 2 diabetes (T2D). His daily average glucose reached $280 \mathrm{mg} / \mathrm{dL}$ with a peak glucose at 398 $\mathrm{mg} / \mathrm{dL}$ and his $\mathrm{HbA1C}$ was at $10 \%$ in 2010. Since 2005, he has suffered many kinds of diabetes complications, including five cardiac episodes (without having a stroke), foot ulcer, renal complications, bladder infection, diabetic retinopathy, and hypothyroidism.

As of 9/30/2020, his daily average glucose is approximately 106 $\mathrm{mg} / \mathrm{dL}$ and $\mathrm{HbA1C}$ at $6.1 \%$. It should be mentioned that he started to reduce the dosage of his three different diabetes medications (maximum dosages) in early 2013 and finally stop taking them on $12 / 8 / 2015$. In other words, his glucose record since 2016 to the present is totally "medication-free".

Beginning on $1 / 1 / 2012$, he started to collect his weight value in the early morning and his glucose values four times a day: FPG $\mathrm{x} 1$ in the early morning and PPG $\mathrm{x} 3$ at two hours after the first bite of each meal. Since $1 / 1 / 2014$, he also started to collect his carbs/sugar amount in grams and post-meal walking steps. Prior to these two dates, especially during the period of 2010 to 2012, the manually collected biomarkers and lifestyle details were scattered and unorganized. Therefore, those annualized data from 2010 to 2012 or 2014 were guesstimated values with his best effort. It should be further mentioned that on $1 / 1 / 2013$, he began to reduce his dosages of three diabetes educations step by step. By 1/1/2015, he was only taking $500 \mathrm{mg}$ of Metformin for controlling his diabetes conditions. Finally, he completely ceased taking Metformin on 12/8/2015; therefore, since 1/1/2016, his body has been completely free of any diabetes medications.

\section{Other Research Results}

Recently, a Danish medical research team has published an article on JAMA which emphasizes a strengthen lifestyle program can "reverse" T2D. This program includes a weekly exercise (5-6 times and 30-60 minutes each time), daily walking more than 10,000 steps using smart phone to keep a record, personalized diet and nutritional guidance by healthcare professionals, etc. The observed results from this Danish report are patients' overall HbA1C reduction of $0.31 \%$, and their diabetes medication dosage reduction from $73 \%$ to $26 \%$.

DiRECT research report from UK also indicated that an aggressive weight reduction program can induce improvement on diabetes conditions. This UK program includes low-calories diet for 3-5 months with 825-853 K-calories per day, plus daily walking of 15,000 steps per day. The observed results from this UK report are patients' overall $\mathrm{HbA1C}$ reduction of $0.9 \%$, weight reduction of $10 \mathrm{~kg}$ (or $22 \mathrm{lbs}$.), and reduced diabetes medication dosage as well.

\section{The Author's Approach}

Inspired by the results from the two European studies and based on his own collected big data over the past 10+ years, from 2010 to 2020, he decided to conduct a similar research on his own. He has separated his $10+$ years data into two periods. The first period of 5 years, from 2010 to 2014 , with partially collected and partially guesstimated data under different degrees of medication influence, and the second period of 6 years, from 2015 to 2020, with a complete set of collected raw data stored in software and severs without any medication influence.

His trend of thoughts include a sequence from cause to consequence as listed below from top to bottom:

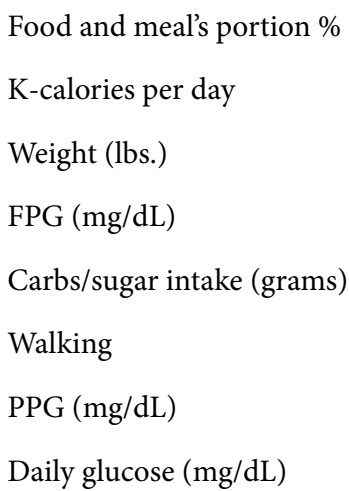

He has further conducted nine calculations of correlation coefficient based on the above parameters to examine the degree of connections between any 2 elements of these total 8 parameters. It should be mentioned that the correlation coefficients can only be done between two data sets, or two curves.

More importantly, in addition to examining the raw data, he also placing an emphasis on the annual change rate percentage, its trend, and their comparisons of these 8 parameters.

\section{Results}

Figure 1 shows his background data table which includes his calculated annual averages of the 8 parameters plus proteins, fat, and daily K-calories, based on his daily data collected during 2010 to 2020 .

Figure 2 depicts the annual change rate percentage of his food (meal portion \%, K-calories, and carbs/sugar) and his weight. In this figure, meal portion and weight have similar change rates which means the less he eats, the lighter his weight. Also, carbs/sugar amount and $\mathrm{K}$-calories have similar change rates which means the less his $\mathrm{K}$-calories, the less his carbs/sugar intake amount.

Figure 3 illustrates the similar trend of annual data of his weight and three food components (meal portion, K-calories, and carbs/ sugar amount).

Exercise is a missing component from this figure which is also essential on weight reduction. The more he eats, the higher intake amounts of his K-calories and his carbs/sugar as well. During the past decade on his effort for weight reduction, he has focused on reducing both of his meal portion percentage and carb/sugar intake amount. As 
Gerald C Hsu (2020) Self-Recovery of Pancreatic Beta Cell's Insulin Secretion Based on 10+ Years Annualized Data of Food, Exercise, Weight, and Glucose Using GH-Method: Math-Physical Medicine (No. 339)

\begin{tabular}{|c|c|c|c|c|c|c|c|c|c|c|c|c|c|}
\hline & $Y 2010$ & 12011 & $Y 2012$ & 12013 & Y2014 & Y2015 & $Y 2016$ & $Y 2017$ & $Y 2018$ & $Y 2019$ & $Y 2020$ & 11-yrs Avg & 6-yrs Avg \\
\hline Carbs/Sugar (g) & 40 & 35 & 33 & 30 & 25 & 20 & 15 & 14 & 15 & 13 & 12 & 23 & 15 \\
\hline Protein (g) & 40 & 35 & 33 & 30 & 25 & 20 & 15 & 16 & 15 & 16 & 15 & 24 & 16 \\
\hline Fat $(g)$ & 40 & 35 & 33 & 30 & 22 & 18 & 11 & 11 & 9 & 11 & 7 & 21 & 11 \\
\hline K-Calories & 2720 & 2380 & 2244 & 2040 & 1601 & 1288 & 885 & 860 & 829 & 844 & 706 & 1491 & 902 \\
\hline Meals Portion (\%) & 150 & 133 & 120 & 115 & 105 & 94 & 88 & 85 & 84 & 76 & 67 & 102 & 82 \\
\hline Weight (lbs) & 220 & 198 & 189 & 183 & 177 & 175 & 173 & 174 & 171 & 173 & 171 & 182 & 173 \\
\hline Walking (Steps) & 2000 & 3000 & 4000 & 7564 & 11767 & 14997 & 17017 & 17863 & 18458 & 15742 & 15882 & 11663 & 16660 \\
\hline Glucose (mg/dL) & 280 & 230 & 165 & 132 & 135 & 129 & 119 & 117 & 116 & 114 & 108 & 150 & 117 \\
\hline PPG (mg/dt) & 300 & 250 & 170 & 133 & 137 & 130 & 120 & 117 & 117 & 114 & 109 & 154 & 118 \\
\hline FPG (mg/dl) & 220 & 170 & 150 & 135 & 128 & 121 & 117 & 120 & 114 & 115 & 104 & 136 & 115 \\
\hline Calculated Glucose & 280 & 230 & 165 & 133 & 135 & 128 & 119 & 117 & 116 & 114 & 108 & 150 & 117 \\
\hline Calculated / Measured & $100 \%$ & $100 \%$ & $100 \%$ & $101 \%$ & $100 \%$ & $99 \%$ & $100 \%$ & $100 \%$ & $100 \%$ & $100 \%$ & $100 \%$ & $100 \%$ & $100 \%$ \\
\hline \multirow[t]{2}{*}{ Note: } & Start & Food & Data & Walking & Mi Model & PPG, drug & FPG, carbs & CVD & CKD & Beta Cell & Neuro & with guess & more precise \\
\hline & Y2010 & Y2011 & Y2012 & Y2013 & Y2014 & Y2015 & Y2016 & Y2017 & Y2018 & Y2019 & Y2020 & 11-yrs Avg & 6-yrs Avg \\
\hline Carbs/Sugar (g) & 40 & 35 & 33 & 30 & 25 & 20 & 15 & 14 & 15 & 13 & 12 & 23 & 15 \\
\hline K-Calories (/10) & 272 & 238 & 224 & 204 & 160 & 129 & 88 & 86 & 83 & 84 & 71 & 1491 & 902 \\
\hline Meals Portion (\%) & 150 & 133 & 120 & 115 & 105 & 94 & 88 & 85 & 84 & 76 & 67 & 102 & 82 \\
\hline \multirow[t]{2}{*}{ Weight (lbs) } & 220 & 198 & 189 & 183 & 177 & 175 & 173 & 174 & 171 & 173 & 171 & 182 & 173 \\
\hline & Y2010 & Y2011 & Y2012 & Y2013 & Y2014 & Y2015 & Y2016 & Y2017 & Y2018 & Y2019 & Y2020 & 11-yrs Avg & 6-yrs Avg \\
\hline Carbs/Sugar (g) & 40 & 35 & 33 & 30 & 25 & 20 & 15 & 14 & 15 & 13 & 12 & 23 & 15 \\
\hline Walking (100 Steps) & 20 & 30 & 40 & 76 & 118 & 150 & 170 & 179 & 185 & 157 & 159 & 117 & 167 \\
\hline Glucose (mg/dL) & 280 & 230 & 165 & 132 & 135 & 129 & 119 & 117 & 116 & 114 & 108 & 150 & 117 \\
\hline PPG (mg/dL) & 300 & 250 & 170 & 133 & 137 & 130 & 120 & 117 & 117 & 114 & 109 & 154 & 118 \\
\hline FPG $(\mathrm{mg} / \mathrm{dL})$ & 220 & 170 & 150 & 135 & 128 & 121 & 117 & 120 & 114 & 115 & 104 & 136 & 115 \\
\hline
\end{tabular}

Figure 1: Background data table.

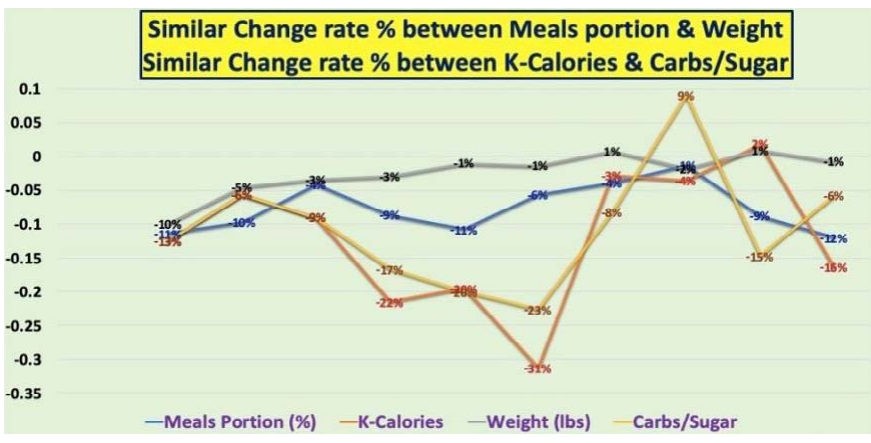

Figure 2: Annual change rates of Weight and Food (meal portion, K-calories, and carbs/ sugar).

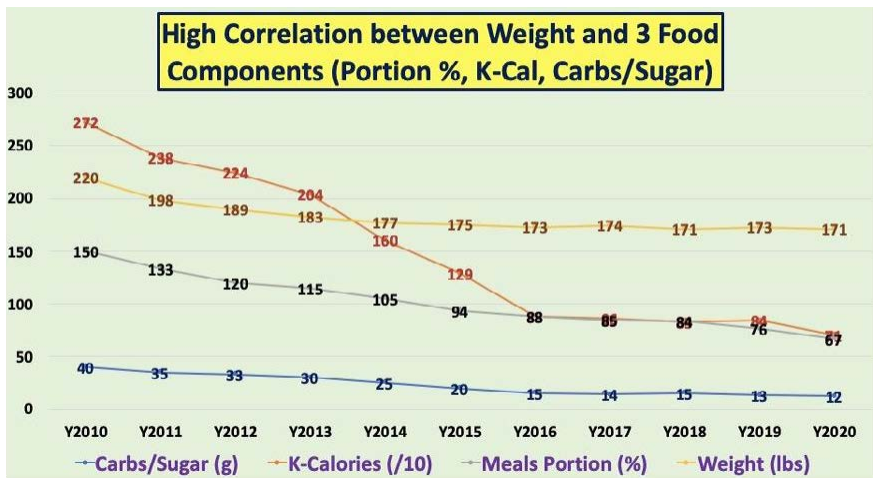

Figure 3: Annual change rates of Weight and Food (meal portion, K-calories, and carbs/ sugar).

a result, he was able to reduce his weight from $220 \mathrm{lbs}(100 \mathrm{~kg})$ and his average glucose from $280 \mathrm{mg} / \mathrm{dL}$ in 2010 to $171 \mathrm{lbs}$. (78 kg) and 106 $\mathrm{mg} / \mathrm{dL}$ in 2020 (without any medication).

Figure 4 reflects the annual change rate percentage of his daily glucose, weight and carbs/sugar amount. In this figure, the change rates of his glucose and weight are remarkably similar, almost a mirror image, which indicates the lower his weight, the lower his glucose. This finding matches the two European studies and the common knowledge possessed by healthcare professionals. The reason for the

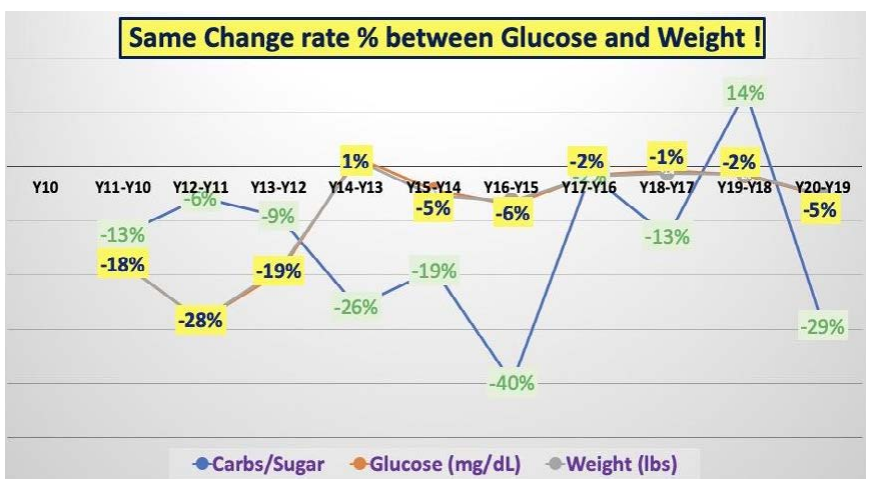

Figure 4: Annual change rates of Weight, Glucose, and Carbs/sugar.

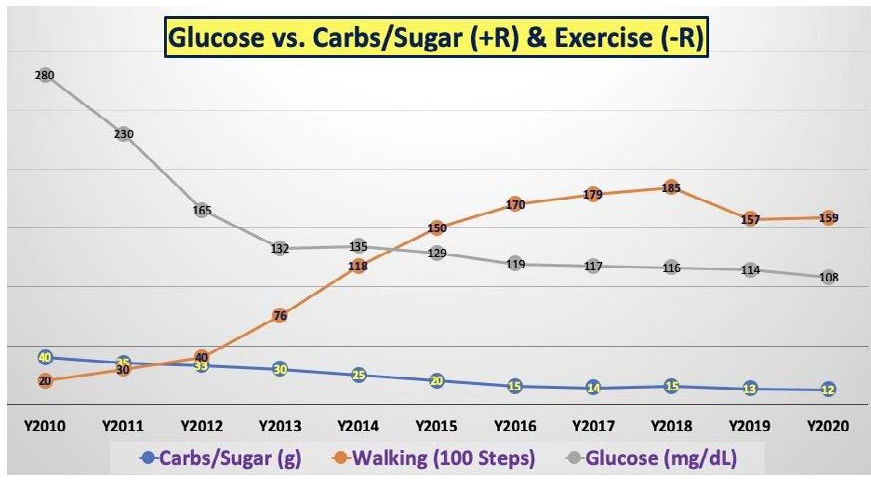

Figure 5: Annual data of Weight, Glucose, and Carbs/sugar.

obviously mismatched change rates between carbs/sugar and glucose or weight is due to the missing component of exercise which is equally important on glucose reduction.

Figure 5 focuses exclusively on the relationships among data of glucose, carbs/sugar, and exercise. The positive correlation coefficient between glucose and carbs/sugar is expressed by these two similar moving trends. On the other hand, the negative correlation coefficient between glucose and exercise (walking) is expressed by these two opposite moving trends. 


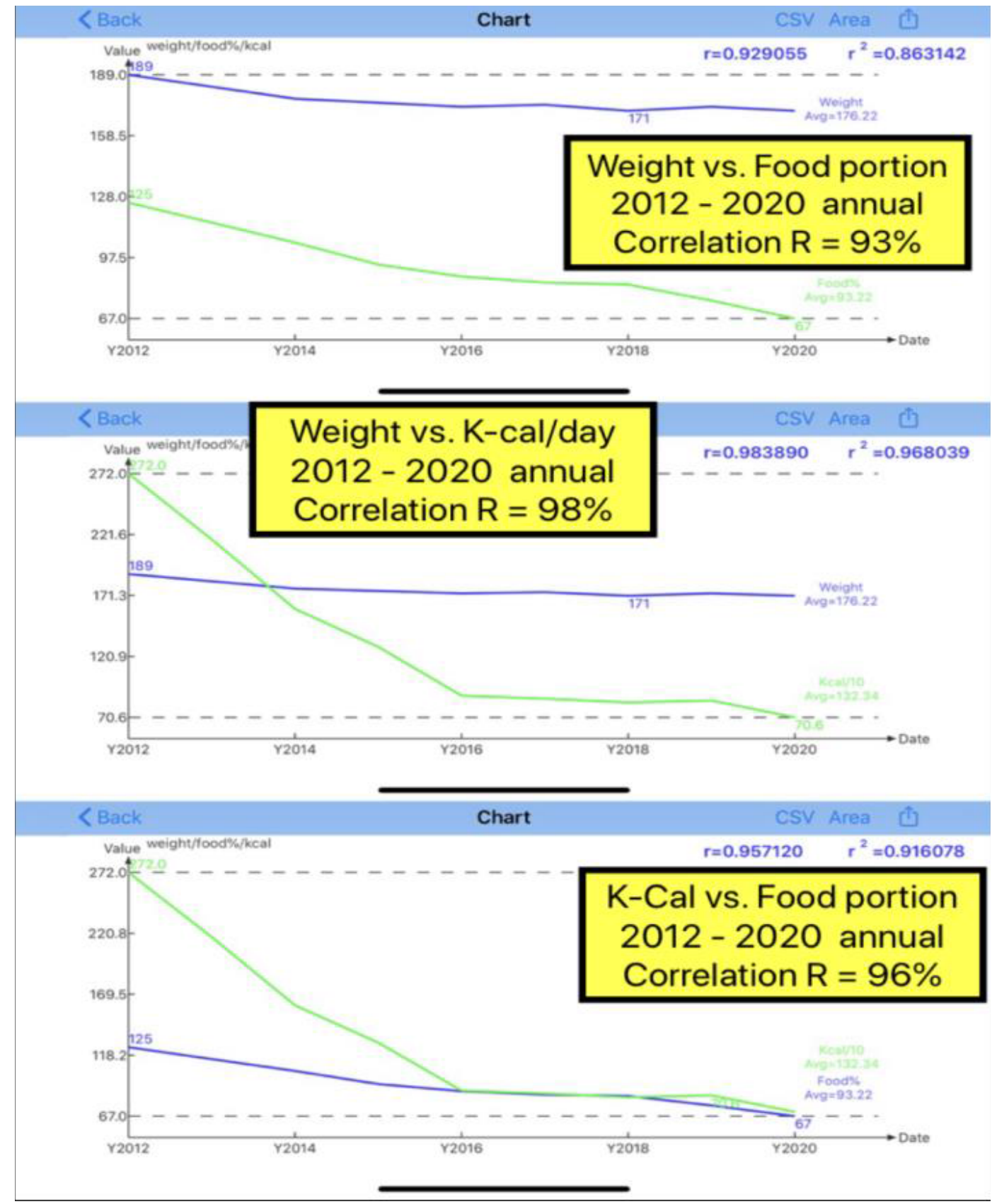

Figure 6: Correlation coefficients among Weight, K-calories, meal portion.

Figures 6-8 collectively collective together to show the 9 sets of calculated correlation coefficients among those 8 listed elements in above section of Methods. A better illustration of these three figures can be found in a table, where all of the calculated correlations are above $90 \%$, which means they are highly connected to each other (Figure 9). Even the correlation of $-89 \%$ between glucose and walking exercise is also extremely high in a negative manner.

Figure 10 reveals the detailed annual change rates of 8 elements for a $10+$ year period from 2010 to 2020 . It should be pointed out that his average change rates within 6 years from 2015 through 2020 are $2.7 \%$ per year for both FPG and PPG, and 3.4\% for daily glucose. This conclusion is similar to his six previously published papers regarding his pancreatic beta cell's self-recovery rate of insulin secretion. Most likely, his beta cells insulin production and functionality have been repaired about $16 \%$ during the past 6 years or $27 \%$ during the past 10 years at a self-repair rate of $2.7 \%$ per year.

Here is the summary of his findings:

His successful weight reduction, from $220 \mathrm{lbs}$. in 2010 to 171 lbs. in 2020, comes from his food portion reduction and exercise increase.

His lower carbs/sugar intake amount, from 40 grams in 2010 to 12 grams in 2020, is resulted from his learned food nutrition knowledge and meal portion reduction, from $150 \%$ in 2010 to $67 \%$ in 2020 . 


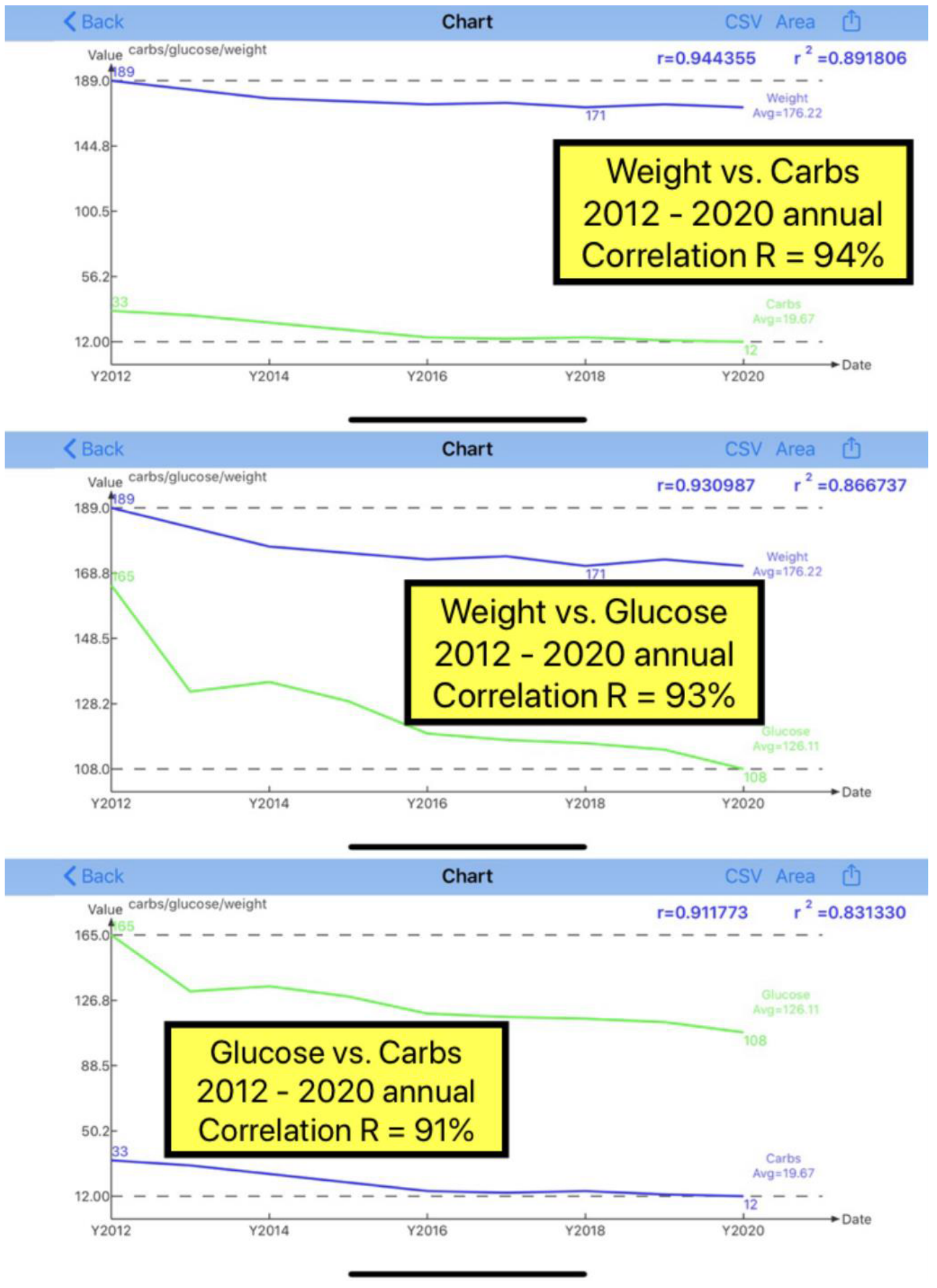

Figure 7: Correlation coefficients among Weight, Glucose, Carbs/sugar.

His weight reduction contributes to his FPG reduction, from 220 $\mathrm{mg} / \mathrm{dL}$ in 2010 to $104 \mathrm{mg} / \mathrm{dL}$ in 2020. His carbs/sugar control and increased walking steps, from 2,000 steps in 2010 to 16,000 steps in 202, have contributed to his PPG reduction, from $300 \mathrm{mg} / \mathrm{dL}$ in 2010 to $109 \mathrm{mg} / \mathrm{dL}$ in 2020. When both FPG and PPG are reduced, his daily glucose is decreased as well, from $280 \mathrm{mg} / \mathrm{dL}$ in 2010 to $108 \mathrm{mg} / \mathrm{dL}$ in 2020 .
His damaged beta cell's insulin production and functionality, most likely, have been repaired about $16 \%$ for the past 6 years or $27 \%$ in the past 10 years at a self-repair rate of $2.7 \%$ per year.

\section{Summary}

To date, the author has written seven papers discussing his pancreatic beta cell's self-recovery of insulin secretion. In his first six papers [2-7], he used several different "cutting angles" or "analysis 


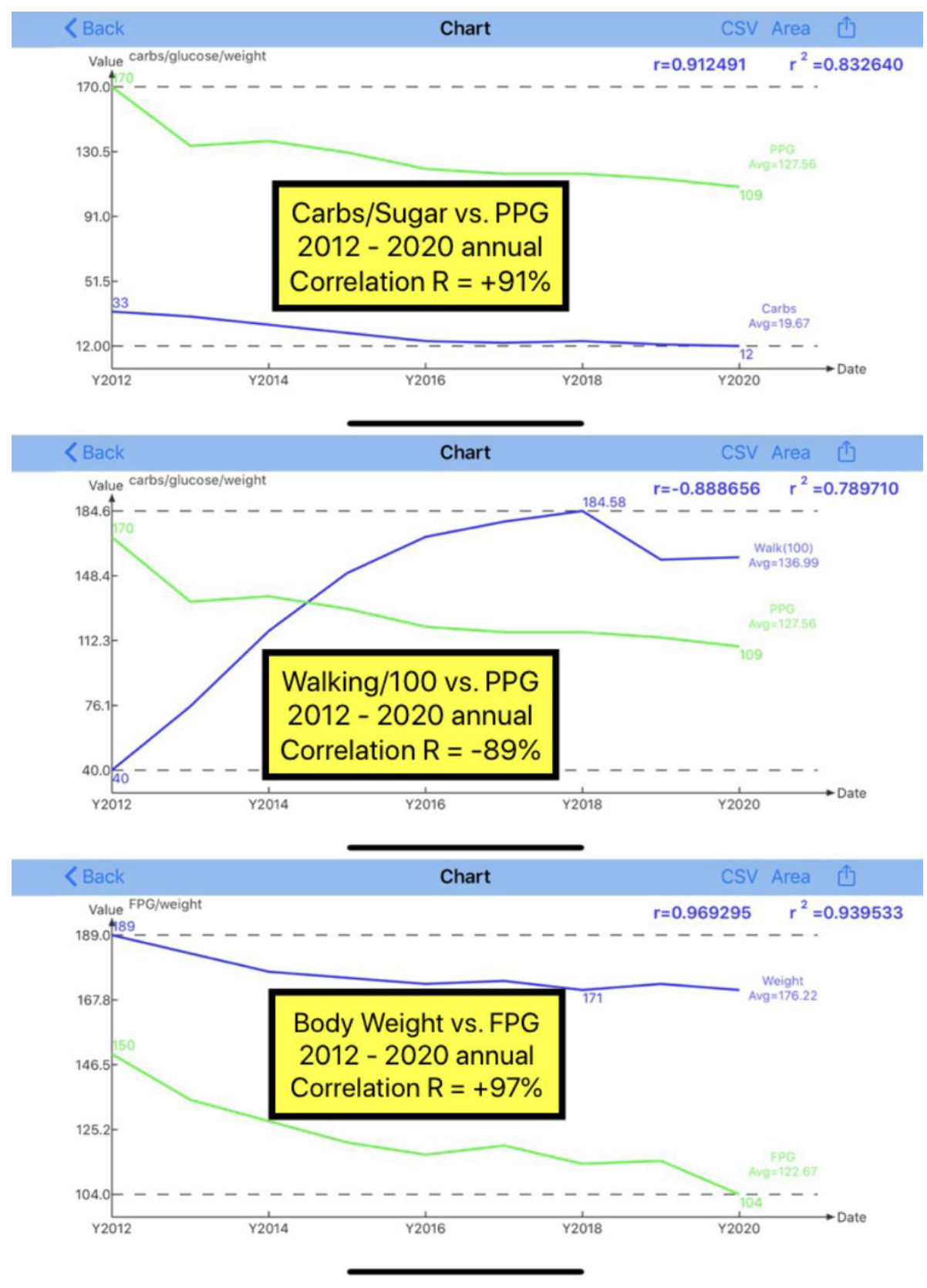

Figure 8: Correlation coefficients among PPG, Carb/sugar, Walking, FPG, Weight.

\begin{tabular}{|l|c|c|c|c|c|c|c|c|}
\hline Correlation & Weight & Food Portion & K-Cal / day & Carbs/Sugar & Glucose & PPG & FPG & Walking \\
\hline Weight & & $93 \%$ & $98 \%$ & $94 \%$ & $93 \%$ & & $97 \%$ & \\
\hline Food Portion & $93 \%$ & & $96 \%$ & & & & & \\
\hline K-Cal / day & $98 \%$ & $96 \%$ & & & & & & \\
\hline Carbs/Sugar & $94 \%$ & & & & $91 \%$ & $91 \%$ & & \\
\hline Glucose & $93 \%$ & & & $91 \%$ & & & & \\
\hline PPG & & & & $91 \%$ & & & & $-89 \%$ \\
\hline FPG & $97 \%$ & & & & & & & \\
\hline Walking Steps & & & & & & $-89 \%$ & & \\
\hline
\end{tabular}

Figure 9: A combined data table of 9 correlation coefficients among 8 elements. 
Gerald C Hsu (2020) Self-Recovery of Pancreatic Beta Cell's Insulin Secretion Based on 10+ Years Annualized Data of Food, Exercise, Weight, and Glucose Using GH-Method: Math-Physical Medicine (No. 339)

\begin{tabular}{|c|c|c|c|c|c|c|c|c|c|c|c|c|c|}
\hline Reduction \% & Y10 & Y11-Y10 & $\mathrm{Y} 12-\mathrm{Y} 11$ & $Y 13-Y 12$ & Y14-Y13 & Y15-Y14 & Y16-Y15 & Y17-Y16 & Y18-Y17 & Y19-Y18 & Y20-Y19 & 10-yrs Rate & 5-yrs Rate \\
\hline Meals Portion (\%) & & $-11 \%$ & $-10 \%$ & \begin{tabular}{|l|}
$-4 \%$ \\
\end{tabular} & \begin{tabular}{|l|}
$-9 \%$ \\
\end{tabular} & \begin{tabular}{|l|}
$-11 \%$ \\
\end{tabular} & $-6 \%$ & $-4 \%$ & $-1 \%$ & $-9 \%$ & $-12 \%$ & $-8 \%$ & $\begin{array}{r}-6 \% \\
\end{array}$ \\
\hline K-Calories & & $-13 \%$ & $-6 \%$ & $-9 \%$ & $-22 \%$ & $-20 \%$ & $-31 \%$ & $-3 \%$ & $-4 \%$ & $2 \%$ & $-16 \%$ & $-12 \%$ & $-10 \%$ \\
\hline Weight (lbs) & & $-10 \%$ & $-5 \%$ & $-3 \%$ & $-3 \%$ & $-1 \%$ & $-1 \%$ & $1 \%$ & $-2 \%$ & $1 \%$ & $-1 \%$ & $-2 \%$ & $-0.5 \%$ \\
\hline Reduction \% & $\mathrm{Y10}$ & $\mathrm{Y} 11-\mathrm{Y} 10$ & Y12-Y11 & Y13-Y12 & $Y 14-Y 13$ & Y15-Y14 & Y16-Y15 & Y17-Y16 & Y18-Y17 & Y19-Y18 & Y20-Y19 & 10-yrs Rate & 5-yrs Rate \\
\hline Carbs/Sugar & & $-13 \%$ & $-6 \%$ & $-9 \%$ & $-26 \%$ & $-19 \%$ & $-40 \%$ & $-2 \%$ & $-13 \%$ & $14 \%$ & $-29 \%$ & $-14 \%$ & $-14 \%$ \\
\hline Glucose (mg/dt) & & $-18 \%$ & $-28 \%$ & $-20 \%$ & $2 \%$ & $-4 \%$ & $-7 \%$ & $-2 \%$ & $-1 \%$ & $-2 \%$ & $-5 \%$ & $-9 \%$ & $-3.4 \%$ \\
\hline FPG (mg/dL) & & $-23 \%$ & $-12 \%$ & $-10 \%$ & $-6 \%$ & $-6 \%$ & $-3 \%$ & $2 \%$ & $-5 \%$ & $1 \%$ & $-9 \%$ & $-7 \%$ & $-2.7 \%$ \\
\hline PPG (mg/dL) & & $-23 \%$ & $-12 \%$ & $-10 \%$ & $-6 \%$ & $-6 \%$ & $-3 \%$ & $2 \%$ & $-5 \%$ & $1 \%$ & $-9 \%$ & $-7 \%$ & $-2.7 \%$ \\
\hline
\end{tabular}

Figure 10: A combined data table of annual change rates of 7 elements, especially glucose change rates of $2.7 \%$.

approaches" to delve deeper into this complex biomedical subject and achieved consistent results within the range of $2.3 \%$ to $3.2 \%$ of annual self-recovery rate.

He used a quantitative approach with precision to discover and reconfirm his pancreatic beta cell's health state by linking it backwards step-by-step with his collected data of glucose, weight, diet, and exercise. He has produced another dataset for a self-repair rate of $2.7 \%$ which is located right in the middle between $2.3 \%$ and $3.2 \%$ from his previous findings.

In his opinion, type 2 diabetes (T2D) is no longer a non-reversible or non-curable disease. Diabetes is not only "controllable" but it is also "self-repairable", even though at a rather slow rate. He would like to share his research findings and his persistent efforts from the past decade with his medical research colleagues and to provide encouragement to motivate other T2D patients like himself to reverse their diabetes conditions.

\section{References}

1. Hsu, Gerald C. eclaireMD Foundation, USA. "GH-Method: Methodology of mathphysical medicine, No. 54 and No. 310."

2. Hsu, Gerald C. eclaireMD Foundation, USA. "Changes in relative health state of pancreas beta cells over eleven years using GH-Method: math-physical medicine (No. 112)."

3. Hsu, Gerald C. eclaireMD Foundation, USA. "Probable partial recovery of pancreatic beta cells insulin regeneration using annualized fasting plasma glucose via $\mathrm{GH}$ Method: math-physical medicine (No. 133)."

4. Hsu, Gerald C. eclaireMD Foundation, USA. "Probable partial self-recovery of pancreatic beta cells using calculations of annualized fasting plasma glucose using GH-Method: math-physical medicine (No. 138)."

5. Hsu, Gerald C. eclaireMD Foundation, USA. "Guesstimate probable partial selfrecovery of pancreatic beta cells using calculations of annualized glucose data using GH-Method: math-physical medicine (No. 139).'

6. Hsu, Gerald C. eclaireMD Foundation, USA. "Relationship between metabolism and risk of cardiovascular disease and stroke, risk of chronic kidney disease, and probability of pancreatic beta cells self-recovery using GH-Method: Math-Physical Medicine (No. 259)."

7. Hsu, Gerald C. eclaireMD Foundation, USA. "Self-recovery of pancreatic beta cell's insulin secretion based on annualized fasting plasma glucose, baseline postprandial plasma glucose, and baseline daily glucose data using GH-Method: math-physical medicine (No. 297)." 